\title{
Study by Monte Carlo methods of an explosives detection system made up with a D-D neutron generator and NaI(TI) gamma detectors Lenin E. Cevallos Robalino ${ }^{a *}$, Gonzalo Felipe García Fernández ${ }^{a}$, Eduardo Gallego ${ }^{a}$, Karen A. Guzmán-García ${ }^{a}$, Hector Rene Vega-Carrillob

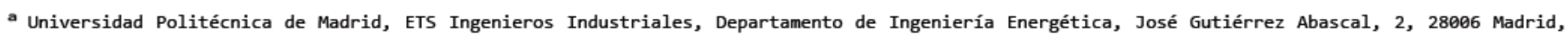 Spain \\ b Unidad Académica de Estudios Nucleares, Universidad Autónoma de Zacatecas, C. Ciprés, 10, 98060 Zacatecas, Zac., Mexico
}

\section{H I G H L I G H T S}

- The performance of a system for explosives detection was determined.

- Detection is based on prompt gamma-rays induced by neutrons produced by a D-D neutron generator.

- The system was tested with $1.5^{\prime \prime} \times 1.0^{\prime \prime}$ and $3^{\prime \prime} \times 3^{\prime \prime} \mathrm{NaI}(\mathrm{Tl})$ scintillators.

- Two explosives, RDX and Ammonium nitrate, were used.

- The performance was evaluated with the MCNP6 code.

\begin{abstract}
A B S T R A C T
Detection of hidden explosives is of utmost importance for homeland security. Several configurations of an Explosives Detection System (EDS) to intercept hidden threats, made up with a Deuterium-Deuterium (D-D) compact neutron generator and NaI (TI) scintillation detectors, have been evaluated using MCNP6 code. The system's response to various samples of explosives, such as RDX and Ammonium Nitrate, is analysed. The D-D generator is able to produce fast neutrons with $2.5 \mathrm{MeV}$ energy in a maximum yield of $10^{10} \mathrm{n} / \mathrm{s}$. It is surrounded by high-density polyethylene to thermalize the fast neutrons and to optimize interactions with the sample inspected, whose emission of gamma rays gives a characteristic spectrum of the elements that constitute it. This procedure allows to determine its chemical composition and to identify the type of substance. The necessary shielding is evaluated to estimate its thicknesses depending on the admissible dose of operation, using lead and polyethylene. The results show that its functionality is promising in the field of national security for explosives inspection.
\end{abstract}

Keywords:

Explosives detection

MCNP6

RDX

Ammonium nitrate

Neutron generator

Deuterium-deuterium reaction

\section{Introduction}

Neutron techniques to identify materials are very diverse. One ap plication having large development has been to prevent terrorist threats with chemical, biological, radiological, nuclear, and explosive mate rials, which pose a clear threat to national security, whose implications are economic and political stability to global level. A clear application is the detection of hidden explosives in air baggage, which is an important issue for all countries in order to avoid a terrorist attack. For some explosive materials the $\mathrm{X}$ ray inspection techniques have some limita tions, thus complementary explosives detection systems (EDS) based on neutron techniques could be useful; however, its acceptance is com plicated [Runkle et al. (2009)].
In addition to explosives, an additional threat is the illicit traffic of drugs hidden in air baggage. Another security global problem are the anti personnel mines, which causes a great number of victims every year. Detection of buried explosives is usually done through metal de tectors which are useless when the mines are made of alloys or plastics [Takahashi et al. (2010)]. In order to detect explosives, drugs or mines the use of technologies based on neutrons could be useful com plementing the metal detectors and the $\mathrm{x}$ ray inspection systems.

Neutron activation analysis (NAA) is a well known and mature technique used for elemental composition determination through the detection and analysis of characteristic gamma rays emitted by nuclei when they are activated with neutrons. This is a non destructive tech nique and has the additional advantages of a high sensitivity and

\footnotetext{
* Corresponding author.

E-mail address: lenin.cevallos.robalino@alumnos.upm.es (L.E. Cevallos Robalino).
} 
specificity [Gozani (1997)]. The key element of neutron based detec tion systems is the neutron source, which must be reliable and compact, like neutron generators using deuterium deuterium (D D) reaction. Neutrons produced in D D reactions are thermalized and the detection of explosives and drugs is made through reactions between neutrons and H, C, O, and N nuclei [Bergaoui et al. (2014)].

Due to the lack of electric charge, neutrons are not affected by the Coulomb field of the atom, thus having a large penetration capacity. Therefore, explosives or drugs can be detected even when they are hidden under layers of soil or high density materials like metals [Kuznetsov et al. (2004)].

\subsection{Explosives}

Explosives differ according to their explosive power, detonation velocity, packing density, water resistance, vapour pressure, sensitivity and suitability for propagation. There are three categories for explosive substances: primary or initiating, secondary o high explosives, and explosive booster [Bernaola Alonso et al. (2013)].

Explosive materials are detected and characterized through their footprint, or signature, being the $\gamma$ rays emitted during neutron inter actions. The amount of explosive is determined by means of the area under the photopeak of those photons. In explosives, the most re presentative elements are oxygen and nitrogen and, to a lesser extent, carbon and hydrogen, as is shown in Table 1 [Alfonso et al. (2013)].

Two of the most commonly used explosive materials are Cyclotrimethylenetrinitramine $\left(\mathrm{C}_{3} \mathrm{H}_{6} \mathrm{~N}_{6} \mathrm{O}_{6}\right)$ known as RDX and Ammonium nitrate $\left(\mathrm{NH}_{4} \mathrm{NO}_{3}\right), \mathrm{AN}$. $\mathrm{RDX}$ is extensively used in the military industry and in antipersonnel mines, while AN is used in homemade explosives. On the other hand, RDX, also known as cyclonite, hexogen, or T4, is the second in strength among the most common explosive substances and is also the main ingredient to produce $\mathrm{C} 3, \mathrm{C} 4$, and compound B (RDX and TNT). It is widely used as detonator and in artillery shells [ACE (1972)].

AN is a colourless, hygroscopic and non flammable compound, mainly use as fertilizer, due to its high nitrogen content. Ammonium is oxidized to nitrate by soil microorganisms, which provides a nitrogen rich plants and crops fertilizer [Parra Terraza et al. (2012)]. When AN is combined with some type of hydrocarbon forms an explosive mixture called ANFO (Ammonium Nitrate and Fuel Oil). Due to its easiness to be dissolved in water, aluminium powder is usually added, becoming a more powerful variety called ANFOAL [Jackson (2017)].

\section{2. $D$ D neutron generator}

The main nuclear reactions used to produce neutrons are shown in Table 2. Of these, the two more commonly used, due to their easy ap plicability and efficiency, are the fusion reactions of light nuclei, D D or deuterium tritium (D T). The two main advantages of compact neutron generators over isotopic neutron sources [Vega Carrillo and Martinez Ovalle (2016)] are their high neutron emission intensity, and that neutron generators can be turned off at any time, thus stopping the

Table 1

Main elements in explosives and energies of their emitted prompt gamma rays by neutron activation.

\begin{tabular}{lll}
\hline Characteristic element & $\begin{array}{l}\text { Relative } \\
\text { abundance }\end{array}$ & $\begin{array}{l}\text { Characteristic } \gamma \text {-ray energy } \\
{[\mathrm{MeV}]}\end{array}$ \\
\hline $\mathrm{O}$ & High & 6.13 \\
$\mathrm{~N}$ & High & 10.83 \\
& & 5.11 \\
& & 2.31 \\
& & 1.54 \\
$\mathrm{C}$ & Low & 4.43 \\
$\mathrm{H}$ & Low & 2.22 \\
\hline
\end{tabular}

Table 2

Main reactions used for neutron production.

\begin{tabular}{ll}
\hline Nuclear reaction & Products \\
\hline $\mathrm{H}^{2}+\mathrm{H}^{2}$ & $\mathrm{He}^{3}(0.82 \mathrm{MeV})+\mathrm{n}(2.45 \mathrm{MeV})$ \\
$\mathrm{H}^{2}+\mathrm{H}^{3}$ & $\mathrm{He}^{3}(3.54 \mathrm{MeV})+\mathrm{n}(14.05 \mathrm{MeV})$ \\
$\mathrm{H}^{1}+\mathrm{Li}^{7}$ & $\mathrm{Be}^{7}(0.21 \mathrm{MeV})+\mathrm{n}(0.03 \mathrm{MeV})$ \\
$\mathrm{H}^{1}+\mathrm{Li}^{7}$ & $\mathrm{Be}^{7}(10.0 \mathrm{MeV})+\mathrm{n}(1.44 \mathrm{MeV})$ \\
$\mathrm{H}^{2}+\mathrm{Li}^{7}$ & $\mathrm{Be}^{8}(1.68 \mathrm{MeV})+\mathrm{n}(13.35 \mathrm{MeV})$ \\
$\mathrm{H}^{1}+\mathrm{Be}^{9}$ & $\mathrm{~B}^{9}(0.18 \mathrm{MeV})+\mathrm{n}(0.023 \mathrm{MeV})$ \\
$\mathrm{H}^{1}+\mathrm{Be}^{9}$ & $\mathrm{~B}^{10}(0.40 \mathrm{MeV})+\mathrm{n}(3.96 \mathrm{MeV})$ \\
&
\end{tabular}

neutron emission [Chichester (2009)] and reducing the safeguards and radiation protection requirements.

Recent technological developments in compact neutron generators have opened a way to use prompt gamma neutron activation analysis, which is an important non destructive tool for elemental analysis and can be applied in several areas such as education, research, industry, medical, archaeological applications, etc. [Bergaoui et al (2014)].

\section{3. $\mathrm{NaI}(\mathrm{Tl})$ scintillator}

Regardless its low resolution, $\mathrm{NaI}(\mathrm{Tl})$ scintillators have a large de tection efficiency [AO (2015); Canberra (2017)], are economic, robust, and do not require a cooling system as high purity Germanium detec tors [Hakimabad et al. (2007)]. These characteristics make them one of the best candidate gamma spectrometer detectors.

\subsection{Moderator}

Polyethylene with density between 0.940 and $0.970 \mathrm{~g} / \mathrm{cm}^{3}$ is known as high density polyethylene (HDPE); the large amount of hydrogen in its composition ( $14 \%$ in weight) makes it useful to moderate and thermalize fast neutrons. Moderation and thermalization of fast neu trons from the generator are important for the quality and accuracy of the process in explosives detection [Yasin and Nasir (2008); Bergaoui (2015)], but also to reduce the neutron dose around the EDS. Neutron shielding and attenuation features of polyethylene is due to its hy drogen concentration. Thus, in EDS, HDPE has a double function as neutron shielding and to produce thermal neutrons that, once captured by hydrogen in the explosive, produce the $\mathrm{H}^{1}(\mathrm{n}, \gamma) \mathrm{H}^{2}$ reaction, having a 0.33 barns cross section and producing a $2.2 \mathrm{MeV}$ prompt gamma ray.

\subsection{Shielding}

Some blends with polyethylene have proved to be ideal shielding materials for neutron due to the ability to internally attenuate the ra diation of the secondary photons generated by neutron's interactions [Chichester and Blackburn (2007)]. Boron (B) is generally used as shielding for thermal neutron, mainly because its absorption cross section is large (767 b) in natural boron [Sakurai et al. (2004)]. The effective absorption and scattering cross sections of some elements are in Table 3 [Sears (1992)].

Borated polyethylene absorbs neutrons leaking out of the arrange ment and the shielding is completed by adding lead to absorb the prompt $\gamma$ rays induced in the polyethylene and in the sample

Table 3

Scattering and absorption cross sections of boron, hydrogen and lead.

\begin{tabular}{lll}
\hline Element & $\boldsymbol{\sigma}_{\mathbf{s}}{ }^{\mathrm{a}}[$ barns] & $\boldsymbol{\sigma}_{\mathbf{a}}{ }^{\mathrm{b}}[$ barns $]$ \\
\hline Boron & 5.24 & 767 \\
Hydrogen & 82.02 & 0.33 \\
Lead & 11.12 & 0.17 \\
\hline
\end{tabular}

a Total bound scattering cross section.

b Absorption cross section for $2200 \mathrm{~m} / \mathrm{s}$ neutrons. 
[Hernandez Adame et al. (2010)]. Moderators, like H, D, Be and gra phite, have the purpose to decrease the neutron energy. Hydrogen rich materials are easy to obtain and are good moderators whose arrange ment must be carefully designed in order to improve the probability to detect the prompt capture gamma rays in the detector [Bedogni et al. (2017); Podgorsak (2016)].

The aim of this work was to evaluate the performance of different configurations of moderator, shielding, detectors and explosive sample on an EDS based on a D D neutron generator, using Monte Carlo methods with the MCNP6 code [Pelowitz et al. (2014)]. Besides the neutron fluence, the ambient dose equivalent was also determined. This work gives a better insight to select the best configuration of the EDS's components.

\section{Materials and methods}

\subsection{Description of the explosives detection system (EDS)}

The EDS has a D D neutron generator, a $\gamma$ ray spectrometer with $\mathrm{NaI}$ (Tl) scintillators, and HDPE as neutron moderator [Bergaoui (2015); Bergaoui et al. (2014)]. These items were modelled with the MCNP6 code [Pelowitz et al. (2014)]. In order to model the D D neutron gen erator, features of a commercially available device, DD 110 model from Adelphi Technology, Inc. were used [ATI (2016)]. The main compo nents of this device are shown in Fig. 1. In the ion source deuterons are produced and using $120 \mathrm{kV}$ are accelerated having $100 \mathrm{keV}$ or higher, then the deuteron current $(55 \mathrm{~mA})$ beam hits a titanium target coated with copper or aluminium, where Deuterium Deuterium reactions are produced, generating ${ }^{3} \mathrm{H}$ and $2.45 \mathrm{MeV}$ neutrons [Bergaoui et al. (2014), Cremer et al. (2008), Bergaoui et al. (2014)].

The overall size of a DD 110 neutron generator is $26.67 \mathrm{~cm}$ dia meter and $63.5 \mathrm{~cm}$ length cylinder. Its general structure is shown in Fig. 2 and surrounded by polyethylene in Fig. 3 [Cremer et al. (2008)].

\subsection{Monte Carlo calculations}

A detailed model of the EDS has been built for the MCNP6 code [Pelowitz et al., (2014)]. In the model, the main components of D D neutron generator were considered, as well as the NaI(Tl) detectors and the HDPE moderator. The materials composition data was taken from Bergaoui et al. (2014). The configuration of the EDS with the poly ethylene and auxiliary equipment is shown in Fig. 4.

Using the VISED software [Schwarz et al. (2008)], the EDS model is shown in Fig. 5.

In the MCNP6 model, the NaI(Tl) detectors were modelled using two different sizes: $3.10 \mathrm{~cm} \times 1.90 \mathrm{~cm}$ and $7.62 \mathrm{~cm} \times 7.62 \mathrm{~cm}$. These models are shown in Fig. 6. In order to emulate the $\mathrm{NaI}(\mathrm{Tl})$ responses the Gaussian Energy Broadening function (GEB) was used [Salgado

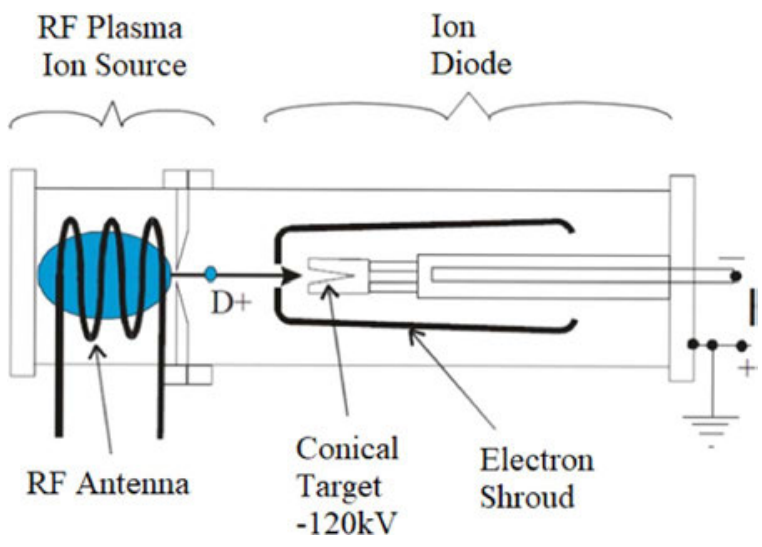

Fig. 1. Main components of a DD-110 Neutron generator [ATI, (2016)].

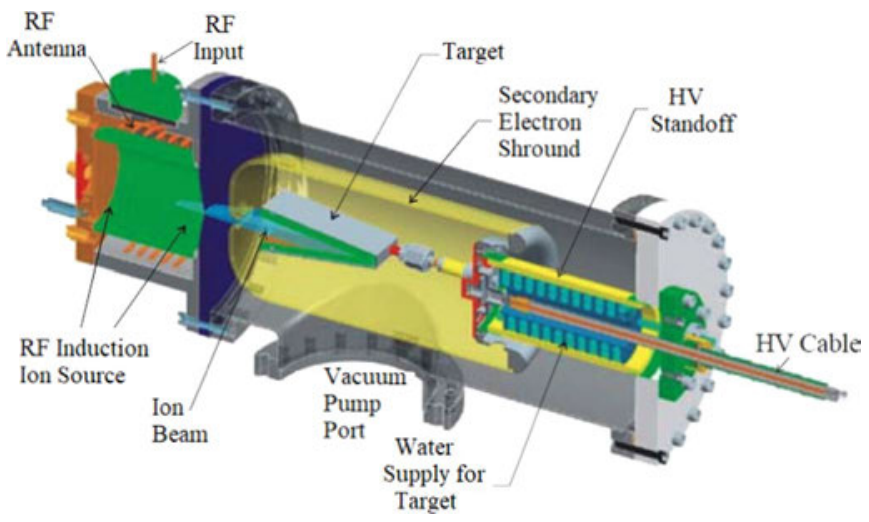

Fig. 2. Cross section of a DD-110 Neutron generator [ATI, (2016)].

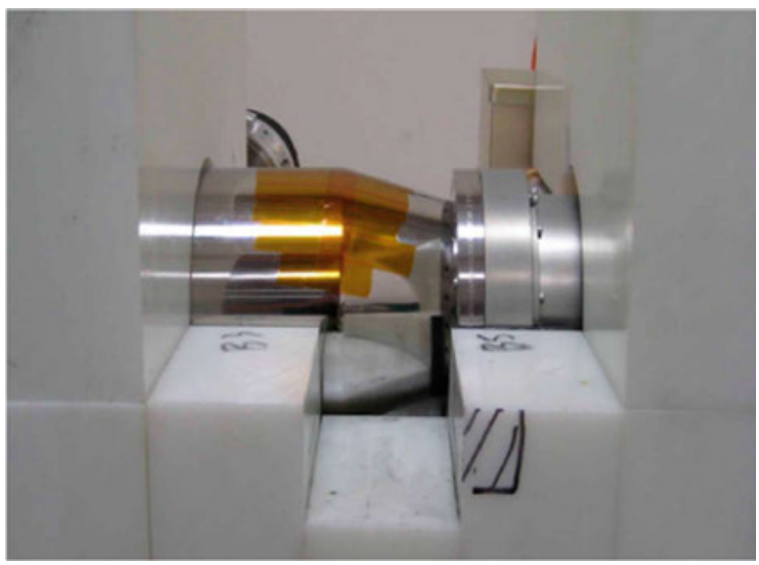

Fig. 3. DD-110 Neutron generator encased in polyethylene moderator [ATI, (2016)].

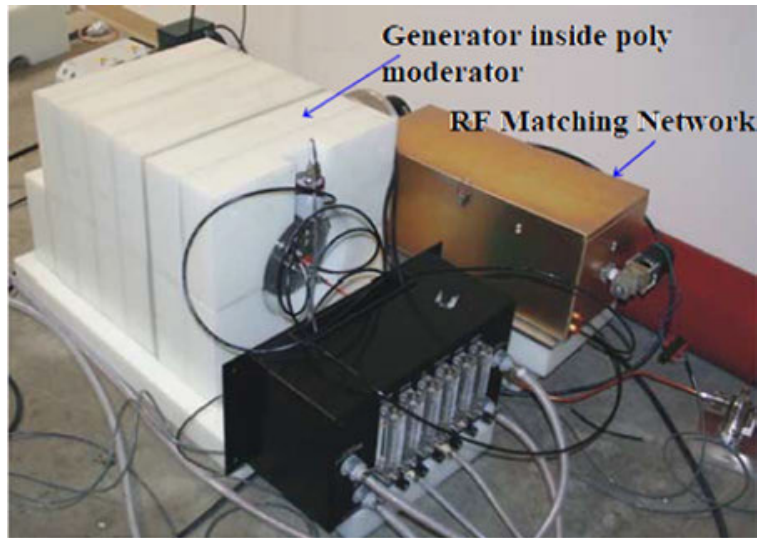

Fig. 4. EDS with polyethylene moderator surrounding the neutron generator [Cremer et al. (2008)].

et al. (2012)]. The GEB coefficients were, $a=-0.0024 \mathrm{MeV}$, b $=0.05165 \mathrm{MeV}^{1 / 2}$ and $\mathrm{c}=2.85838 \mathrm{MeV}^{-1}$ for small detectors [Salgado et al. (2012)], and a $=-0.00789 \mathrm{MeV}, \mathrm{b}=0.06769 \mathrm{MeV}^{1 / 2}$ and $\mathrm{c}=0.21159 \mathrm{MeV}^{-1}$ for the large scintillators [Hakimabad. et al. (2007)].

In the aim to find the best array, in the simulation three different configurations of EDS components were tested. In each configuration, the shape of the device was modified, varying the moderator and shielding geometry while shape and dimensions of neutron generator, $\mathrm{NaI}(\mathrm{Tl})$ detectors, and samples in each array were unchanged. Three simulations were done for each configuration: first, without explosive sample in order to obtain the background; second, with $1 \mathrm{~kg}$ of RDX $\left(1.82 \mathrm{~g} / \mathrm{cm}^{3}\right)$ modelled as $9 \times 9 \times 7 \mathrm{~cm}^{3}$ regular parallelepiped, and 


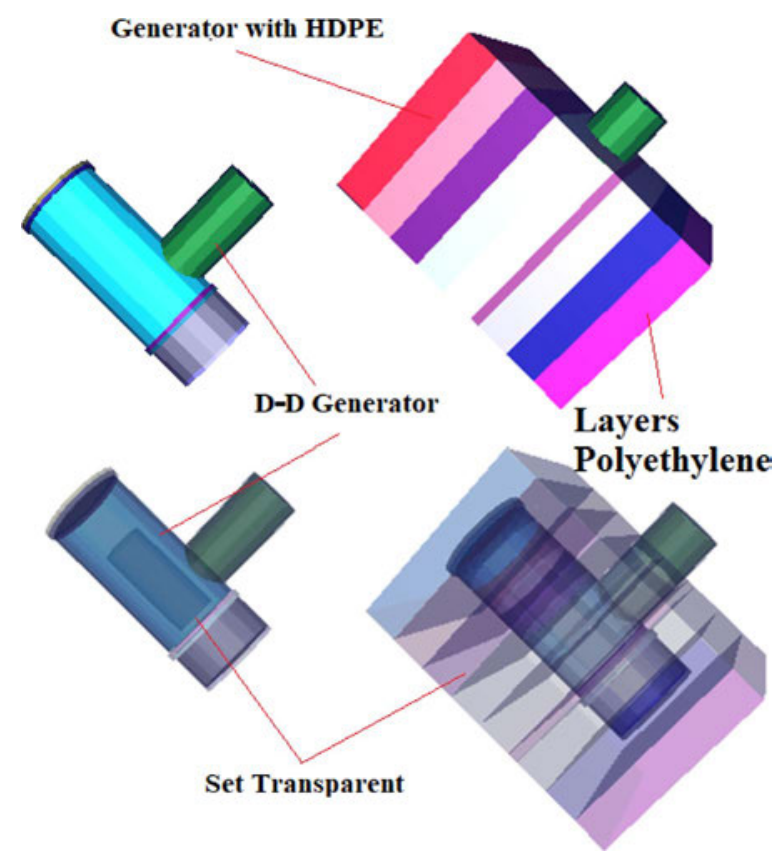

Fig. 5. MCNP6 VISED model of a DD-100 Neutron generator with HDPE.

third, with $1 \mathrm{~kg}$ of AN $\left(1.725 \mathrm{~g} / \mathrm{cm}^{3}\right)$ modelled as $8 \times 8 \times 9 \mathrm{~cm}^{3}$.

In the simulations, the source was located at $60 \mathrm{~cm}$ of the sample centre and it was simulated as a monoenergetic neutron source of $2.45 \mathrm{MeV}$, assuming isotropic emission. Neutrons are transported through the polyethylene and reaching the sample. In order to take into account the transport of thermal neutron the $S(\alpha, \beta)$ treatment was included [Vega Carrillo et al. (2014)]. In the model, the NaI(Tl) de tector was positioned at $13 \mathrm{~cm}$ from the sample, aligning the axial axis of the sample and detectors. Using the f8 tally and the GEB function the $\gamma$ ray pulse heights were calculated. In addition, the total $\gamma$ ray fluence in the detectors was estimated using the $\mathrm{f} 4$ tally. In the calculations, $10^{8}$ histories were used in the aim to have uncertainties lower than 5\%.

Ambient dose equivalent, $\mathrm{H}^{*}(10)$, due to neutrons was estimated at $50,100,150$, and $200 \mathrm{~cm}$ from $0,0,0 \mathrm{~cm}(\mathrm{X}, \mathrm{Y}, \mathrm{Z})$, this point was located in the neutron generator target. $\mathrm{H}^{*}(10)$ was estimated using the f4 tally and the neutron fluence to ambient dose equivalent conversion factors taken from ICRP 74 publication [ICRP (1996)]. Cross sections

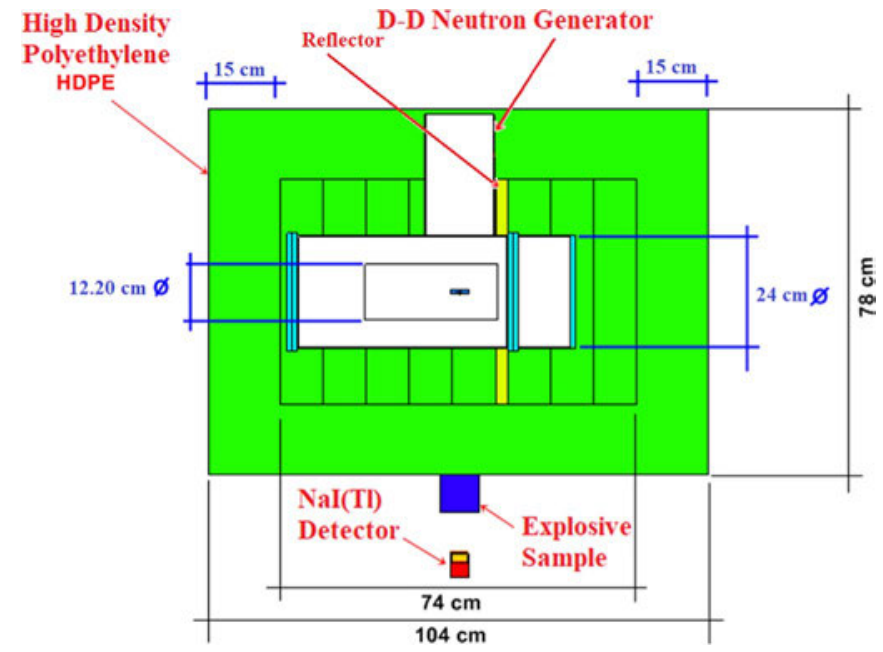

Fig. 7. Configuration 1: MCNP6 model of the DD-110 generator shielded with HDPE.

were taken from the ENDF/B VII library [Pelowitz et al. (2014)]. Total neutron fluence for $2.5 \mathrm{E}(-08), 4.0 \mathrm{E}(-07)$, and $1.0 \mathrm{E}(-06) \mathrm{MeV}$ neu trons in the sample were estimated. Neutron fluence and $H^{*}(10)$ per history were multiplied by $10^{10} \mathrm{n} / \mathrm{s}$, which is the nominal neutron yield of the commercially available neutron generator.

\subsubsection{Configuration 1}

This configuration is shown in Fig. 7. Here, the HDPE thickness was $15 \mathrm{~cm}$, which was included as moderator. In this case, no shielding was included.

\subsubsection{Configuration 2}

In this configuration, HDPE was $15 \mathrm{~cm}$ thick. Then, $8 \mathrm{~cm}$ thick layer of borated polyethylene, and $5 \mathrm{~cm}$ thick lead layer were included. Also, a $31.5 \mathrm{~cm}$ length and $15 \mathrm{~cm}$ long rectangular cavity filled with air was included aiming to increase the thermal neutron fluence in the sample. Figs. 8 and 10 are showing the details of this configuration.

\subsubsection{Configuration 3}

This configuration was alike configuration 2 . Here $15 \mathrm{~cm}$ thick HDPE was used to cover the moderator, followed by layers of $6 \mathrm{~cm}$ thick borated polyethylene and $6 \mathrm{~cm}$ thick lead. Then, another cover

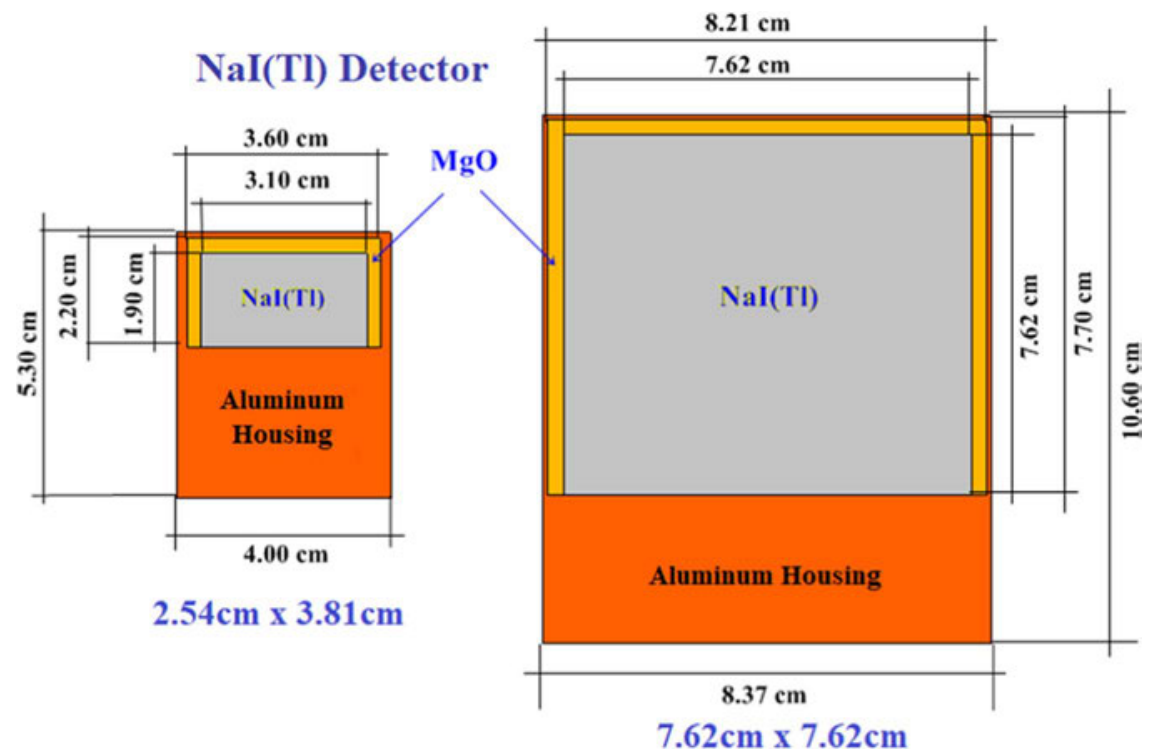

Fig. 6. MCNP6 model of the NaI(Tl) scintillators. 


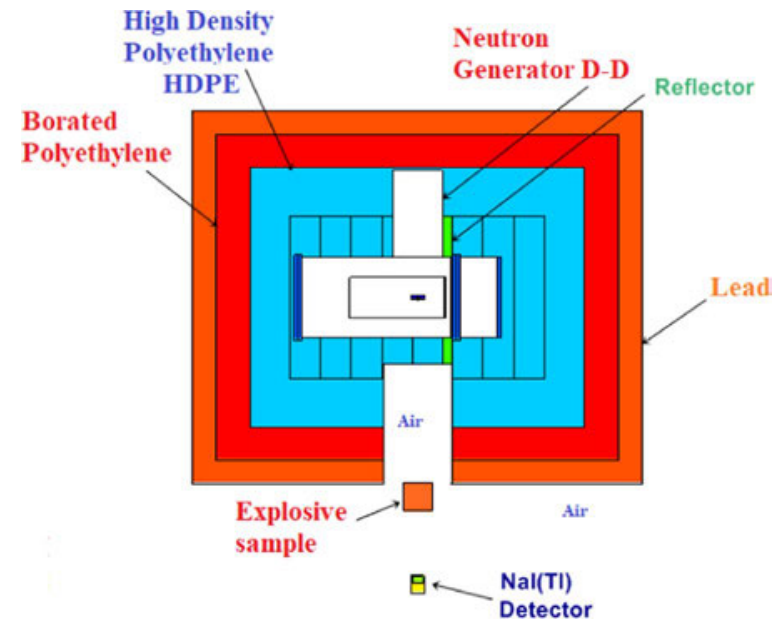

Fig. 8. Configuration 2: MCNP6 model of the DD-110 generator shielded with borated polyethylene and lead.

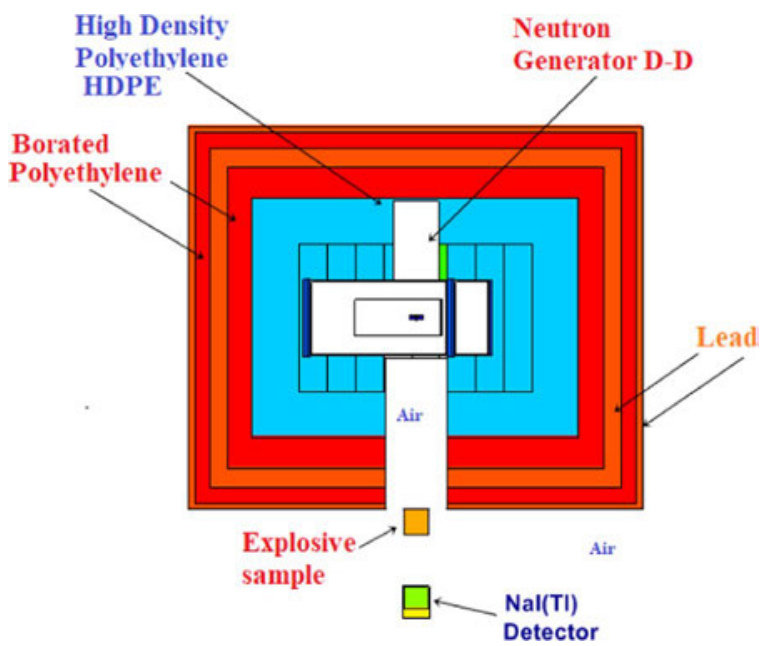

Fig. 9. Configuration 3: MCNP6 model of the DD-110 generator shielded with borated polyethylene and lead.

made of $4.5 \mathrm{~cm}$ thick of borated polyethylene followed by $2.5 \mathrm{~cm}$ thick lead. This configuration also included the rectangular cavity or air window, as shown in Figs. 9 and 10.

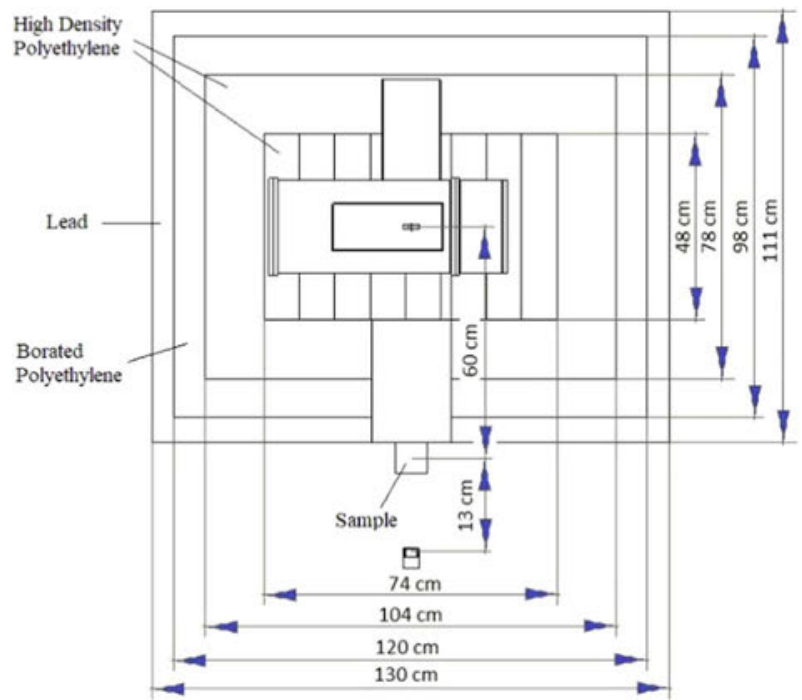

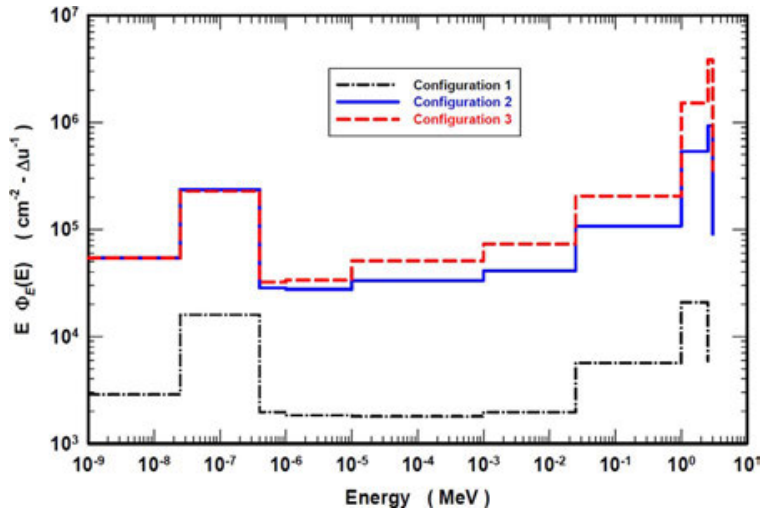

Fig. 11. Neutron spectra for different EDS configurations.

\section{Results and discussion}

In Fig. 11, the neutron spectra in the explosive sample cell for the three configurations are shown. The neutron generator produces monoenergetic neutrons that during transport in the moderator mate rials are slowing down, producing epithermal and thermal neutrons. For configurations 2 and 3, the neutron flux is larger than for config uration 1 at all energies. However, for configuration 1, the thermal neutron component of the spectrum is larger than that in the fast groups. This is probably because in configuration 1 more fast neutrons are leaking, but also because in configurations 2 and 3 the cavity in creases the amount of scattering of fast and epithermal neutrons before they reach the thermal region.

In Fig. 12, the map of ambient dose equivalent rate $\mathrm{H}^{*}(10)$ (in $\mu \mathrm{Sv} /$ h) due to neutrons around the neutron generator is represented for the three configurations. Also for the three configurations, the rate of $\mathrm{H}^{*}(10)$ due to neutrons, in function of distance to the generator target, along the main axis of the generator window (vertical line from the centre in Fig. 12), is shown in Fig. 13. The largest doses are reached at $50 \mathrm{~cm}$ and are reduced as the distance from the neutron generator target increases. Beyond $100 \mathrm{~cm}, \mathrm{H}^{*}(10)$ for configurations 2 and 3 are practically the same. Obviously, the shielding materials in configura tions 2 and 3 results in lower doses.

In Table 4, the $H^{*}(10)$ rate due to neutrons for all configurations in function of the distance to the target is shown, as well as the neutron flux for three main energy groups at the nearest point for the checked sample in each configuration. The values of $H^{*}(10)$ were evaluated for

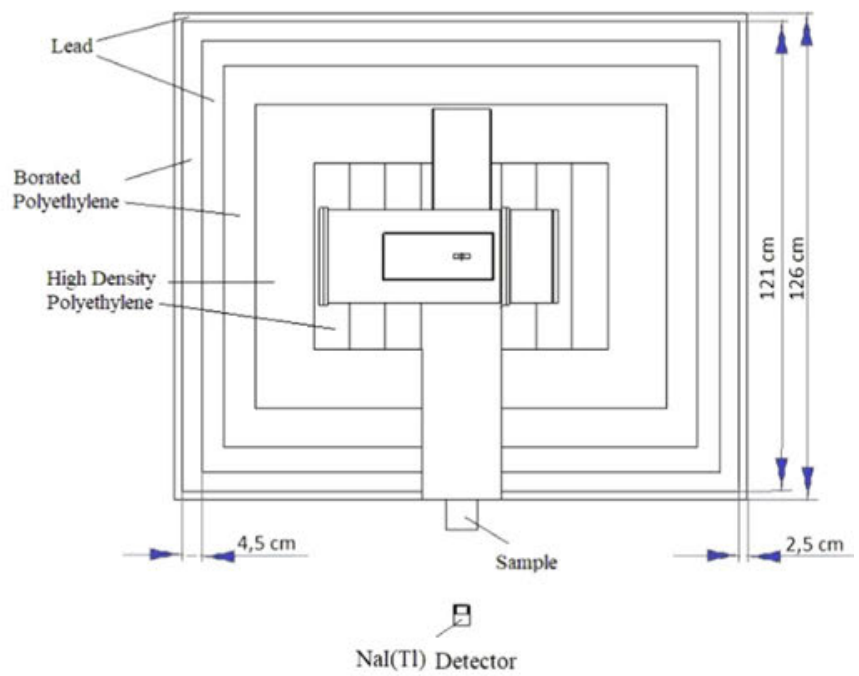

Fig. 10. MCNP6 model dimensions in configuration 2 (left) and configuration 3 (right). 


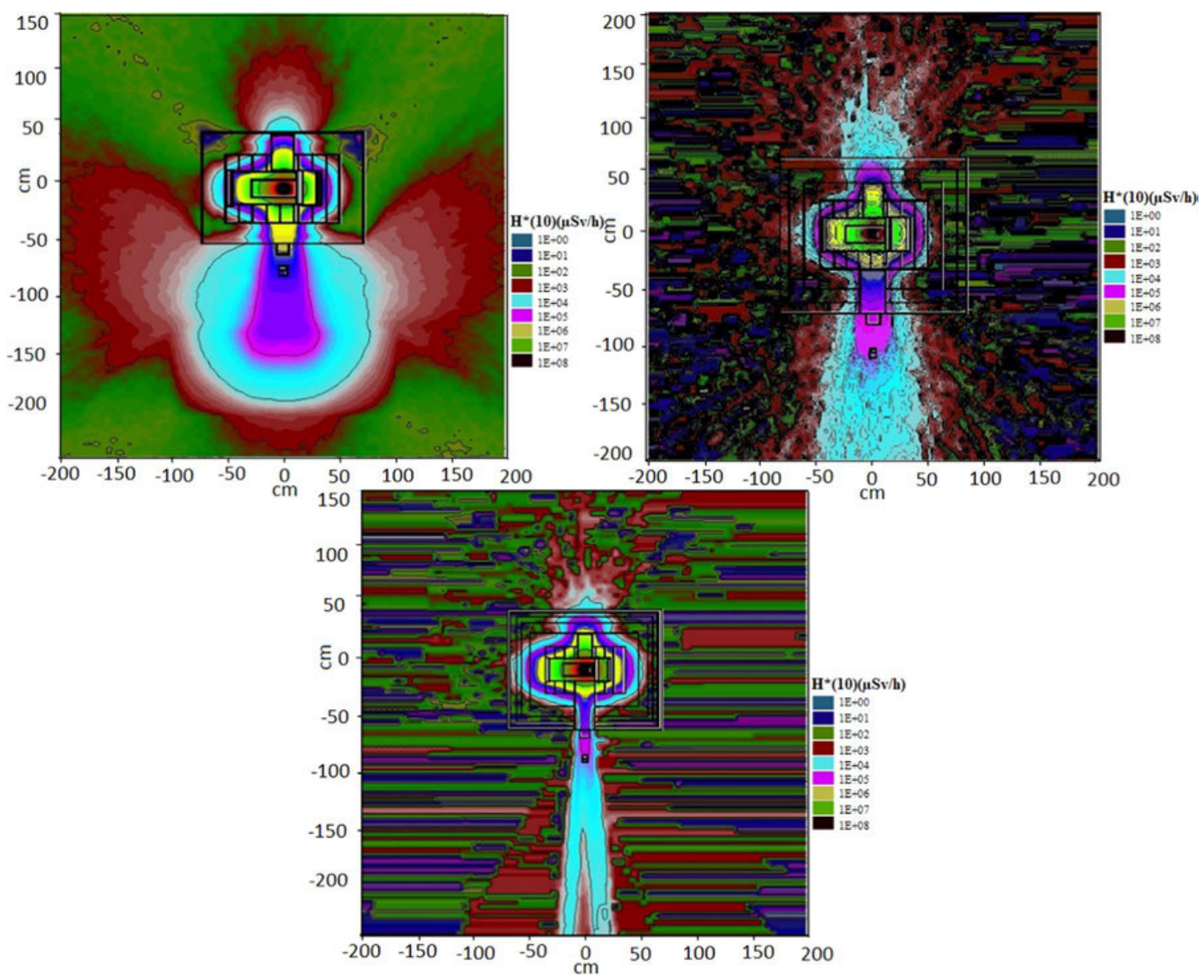

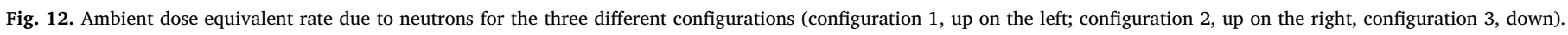

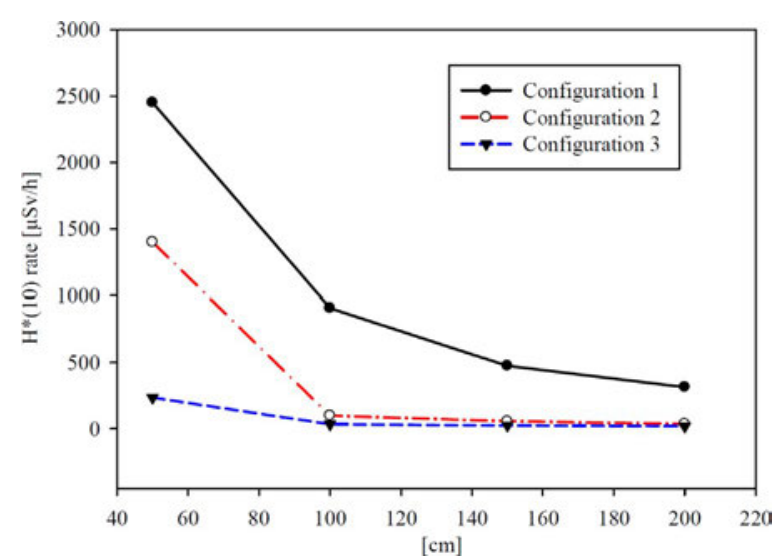

Fig. 13. Ambient dose equivalent rate for different EDS configurations along the main axis.

each configuration considering the shielding and the distance from the centre of the D D generator at 50,100, 150 and $200 \mathrm{~cm}$. For config uration 1 , dose values are higher than for configuration 2 , and this gives doses slightly higher than configuration 3 . This result is due to the ef fect of shielding layers in each configuration.

Neutron flux values were obtained at a distance measured from the centre of the D D generator to the sample, which depending on the configuration of the model, varied from $43 \mathrm{~cm}$ for configuration 1 , $60 \mathrm{~cm}$ for configuration 2 and $67.5 \mathrm{~cm}$ for configuration 3 . Thermal neutron flux increases due to the effect of leaving an air cavity between the generator and the sample, with influence from the moderator and
Table 4

Results of ambient dose equivalent rate $(\mu \mathrm{Sv} / \mathrm{h})$ and neutron flux $\left(\mathrm{cm}^{2} \mathrm{~s}^{1}\right)$ obtained for the three configurations using computational simulations in MCNP6.

\begin{tabular}{|c|c|c|c|}
\hline \multirow[t]{2}{*}{ Distance $[\mathrm{cm}]$} & Configuration 1 & Configuration 2 & Configuration 3 \\
\hline & \multicolumn{3}{|c|}{ Ambient dose equivalent rate (neutrons) $[\mu \mathrm{Sv} / \mathrm{h}]$} \\
\hline 50 & $2.45 \mathrm{E}+03$ & $1.40 \mathrm{E}+03$ & $2.35 \mathrm{E}+02$ \\
\hline 100 & $9.08 \mathrm{E}+02$ & $1.00 \mathrm{E}+02$ & $3.40 \mathrm{E}+01$ \\
\hline 150 & $4.75 \mathrm{E}+02$ & $5.70 \mathrm{E}+01$ & $2.51 \mathrm{E}+01$ \\
\hline 200 & $3.15 E+02$ & $3.60 \mathrm{E}+01$ & $1.90 \mathrm{E}+01$ \\
\hline $\begin{array}{c}\text { Neutron energy }^{\mathrm{a}} \\
{[\mathrm{MeV}]}\end{array}$ & \multicolumn{3}{|c|}{ Neutron flux $\left[\mathrm{cm}^{2} \mathrm{~s}^{1}\right]$} \\
\hline $2.50 \mathrm{E} \quad 08$ & $9.27 \mathrm{E}+03$ & $1.74 \mathrm{E}+05$ & $1.74 \mathrm{E}+05$ \\
\hline $4.00 \mathrm{E} \quad 07$ & $4.43 \mathrm{E}+04$ & $6.53 \mathrm{E}+05$ & $6.31 \mathrm{E}+05$ \\
\hline $1.00 \mathrm{E} \quad 06$ & $1.81 \mathrm{E}+03$ & $2.61 \mathrm{E}+04$ & $2.96 \mathrm{E}+04$ \\
\hline TOTAL & $5.53 \mathrm{E}+04$ & $8.53 \mathrm{E}+05$ & $8.34 \mathrm{E}+05$ \\
\hline
\end{tabular}

${ }^{a}$ Lower values of the three energy groups considered.

neutron absorbers thickness. In this way, neutrons undergo scattering in the moderator in its entire trajectory while reflecting, what causes the increase in flux of thermal neutrons into the sample. On the other hand, the ambient dose equivalent decreases when the thickness of shielding materials is increased. The dose calculations were performed con sidering a limited cubic shaped space of $400 \mathrm{~cm}$ in each side, with the detection system in the centre of the model.

Figs. 1419 display the results of simulations for the three different configurations and different situations, RDX and AN samples compared against background radiation (without explosive sample). Each ex periment is modelled with both, a $1.5^{\prime \prime} \times 1^{\prime \prime}$ and a $3^{\prime \prime} \times 3^{\prime \prime} \mathrm{NaI}(\mathrm{Tl})$ detector. In this way, it has been possible to contrast the different 

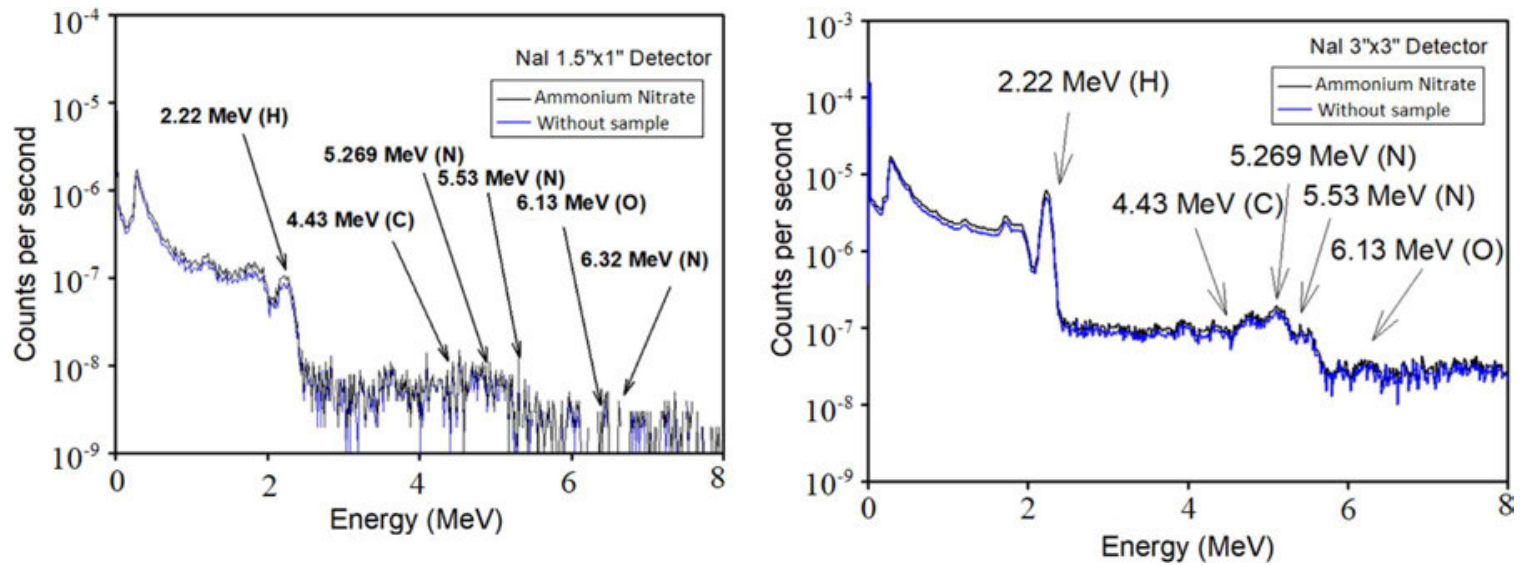

Fig. 14. Spectra obtained by simulating a sample of ammonium nitrate with configuration 1 and different NaI(Tl) detector sizes.
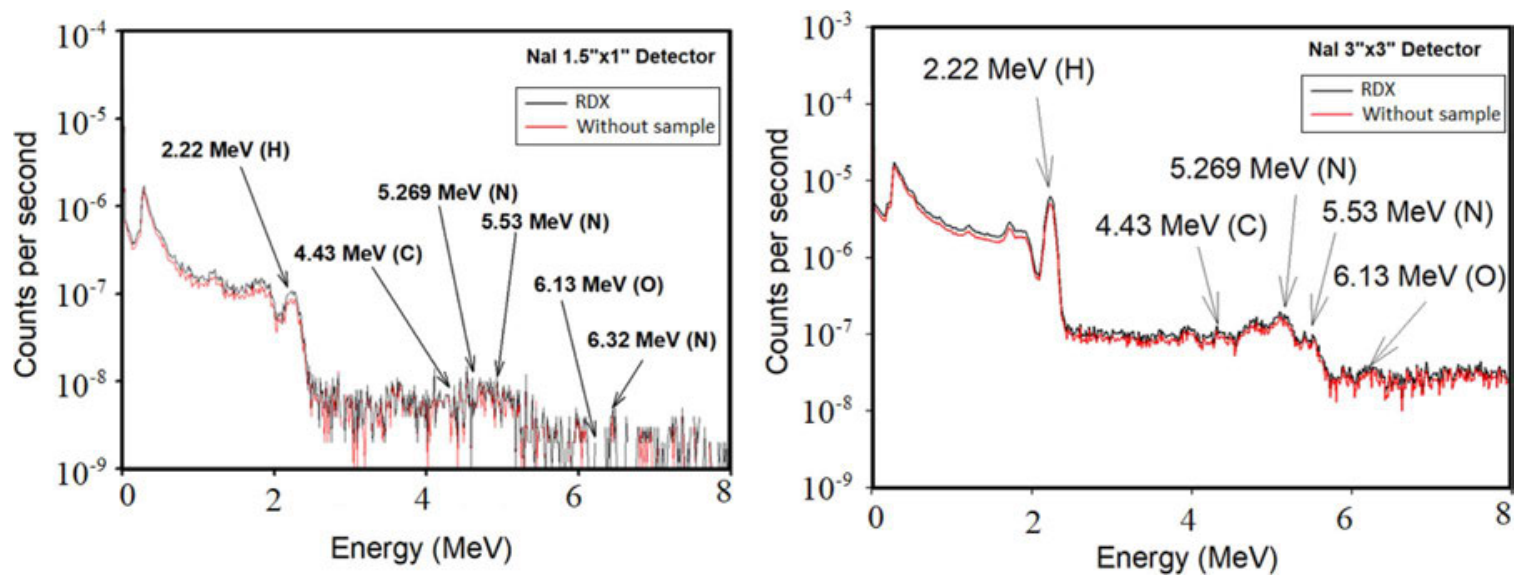

Fig. 15. Spectra obtained by simulating a sample of RDX with configuration 1 and different NaI(Tl) detector sizes.
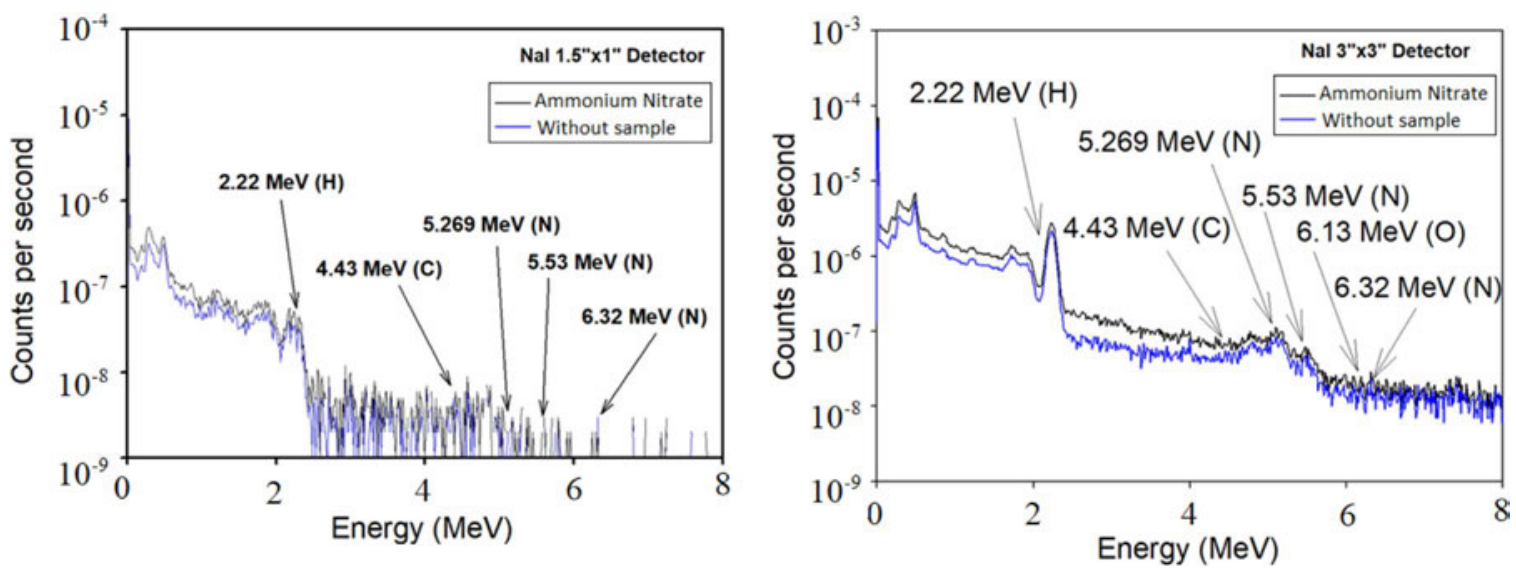

Fig. 16. Spectra obtained by simulating a sample of ammonium nitrate with configuration 2 and different NaI(Tl) detector sizes.

results and select not only the best glass diameter that allows a better visualization of the curves, but also the best configuration to obtain a better spectrum with the purpose of samples characterization and therefore of explosives detection.

From the analysis of results, it is obvious that using configuration 1 it would be difficult to distinguish and identify the explosive sample, even with the larger detector. However, configurations 2 and 3, parti cularly with the large detector, allow obtaining clear spectra separa tion. For configuration 3 , even the small detector is giving a well de fined separation between the spectrum with explosive samples and the signal of the EDS without samples.

\section{Conclusions}

An EDS using neutrons was simulated with MCNP6 trying to find the best configuration to allow identification of explosive materials. The main elements of the EDS is a D D neutron generator, one or two NaI(Tl) scintillators as gamma spectrometer detectors, and HDPE as neutron moderator. The key elements of the EDS have been modelled according to the description given in the manufacturer's data and recent literature. Three different configurations of the EDS have been simulated, varying the geometry of the device, the thickness and materials of the moderator, and the number, position and size of the gamma ray detectors. 

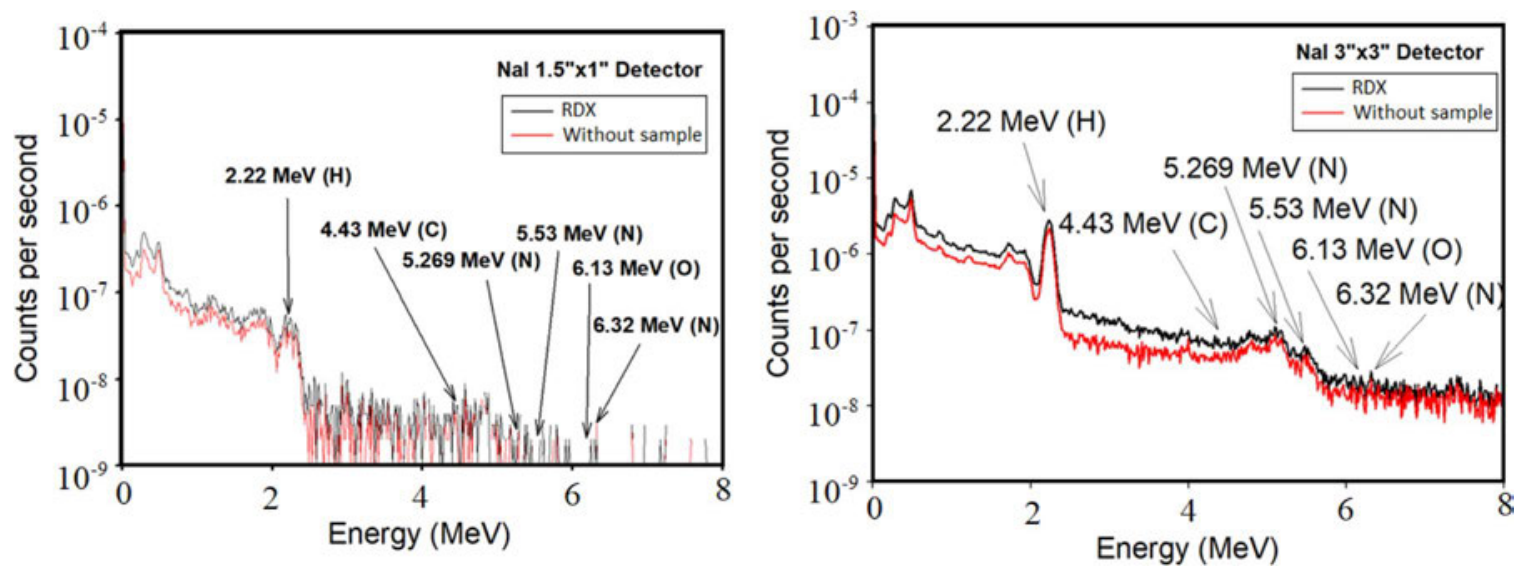

Fig. 17. Spectra obtained by simulating a sample of RDX with configuration 2 and different NaI(Tl) detector sizes.
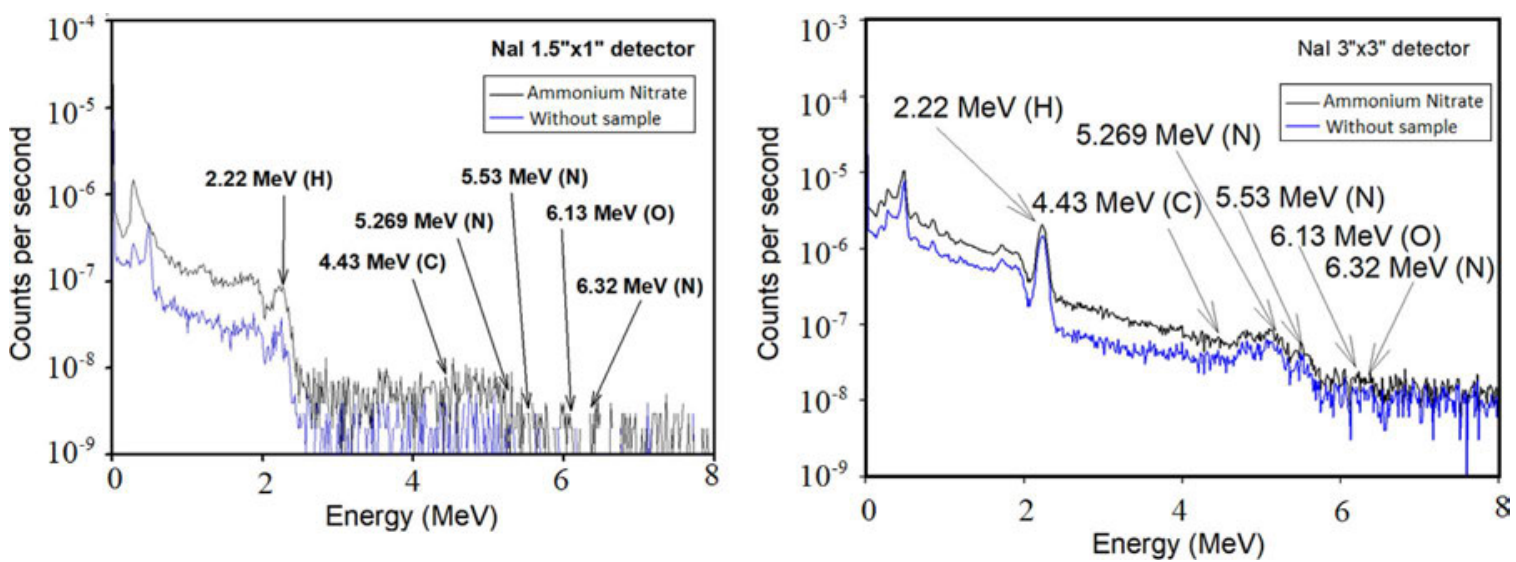

Fig. 18. Spectra obtained by simulating a sample of ammonium nitrate with configuration 3 and different $\mathrm{NaI}(\mathrm{Tl})$ detector sizes.
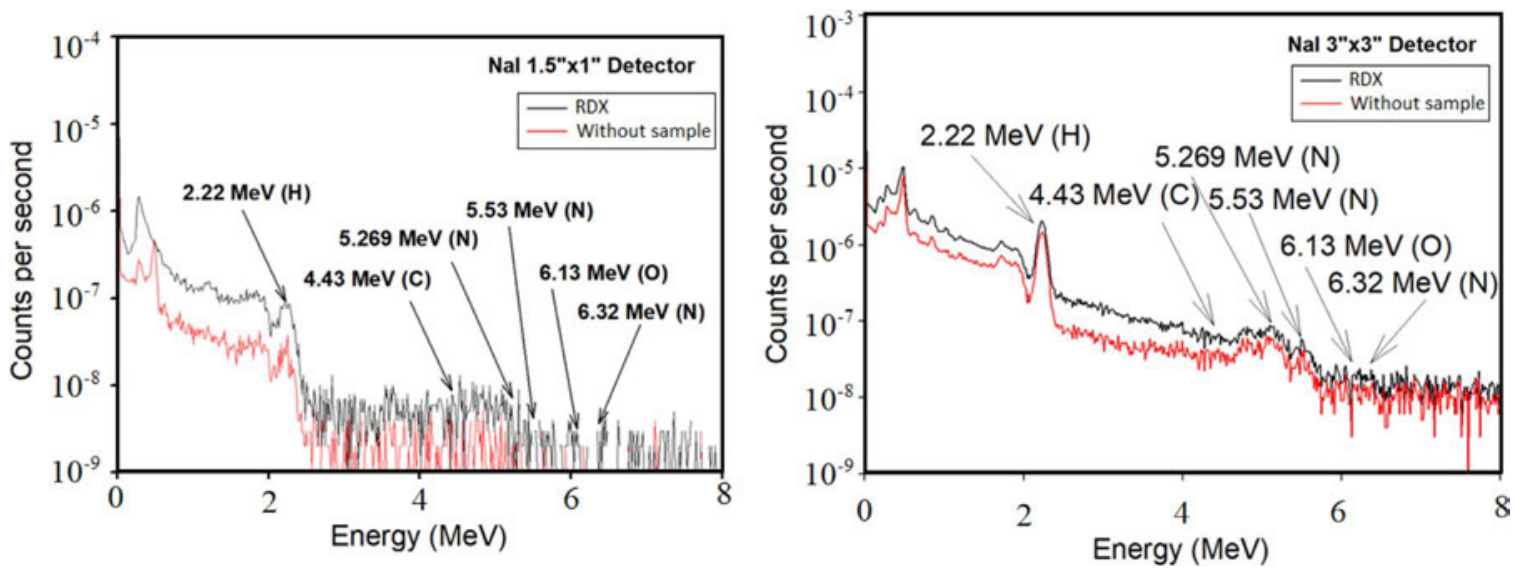

Fig. 19. Spectra obtained by simulating a sample of RDX with configuration 3 and different NaI(Tl) detector sizes.

The obtained results show that backscattering can increase the flux of thermal neutrons, necessary to characterize the samples, by obser ving the prompt gamma rays produced by activation of key elements in the materials, such as $\mathrm{N}, \mathrm{O}, \mathrm{H}$ and $\mathrm{C}$. These elements are present in almost all explosives and their relative fractions are important to identify explosive substances.

From the calculations performed, we can conclude that the neutron flux increases when there is a cavity inside the system, configuration 3 , and the scintillator has the larger size glass of $3^{\prime \prime} \times 3^{\prime \prime}$, which helps to get a better quality in the peak resolution.
Each EDS configuration was simulated in three different scenarios: without explosive sample (background), with RDX explosive, and with AN explosive. In all cases, the explosive was correctly identified through the study of the characteristic photopeaks of their key elements (N, O, H, C).

In summary, the best thermal neutron flux is obtained with con figurations 2 and 3, having a lateral inside cavity in the moderator shielding HDPE, whereas configuration 3, with double layer of shielding with borated polyethylene and lead, yields lower ambient dose equivalent, as expected. In order to obtain a good spectrum that 
adequately characterizes the key elements of the samples the best choice would be the larger sodium iodide glass, diameter $3^{\prime \prime} \times 3^{\prime \prime}$.

\section{Acknowledgments}

L. Cevallos Robalino thanks the National Secretary for Higher Education, Science and Technology of Ecuador (SENESCYT), for the scholarship to carry out postgraduate studies in Madrid, Spain.

G.F. García Fernández thanks the Chair of Nuclear Safety "Federico Goded" between the Nuclear Safety Council (CSN) of Spain and Universidad Politecnica de Madrid (UPM) for the grant received to initiate Ph.D. studies (No. SN170541001).

\section{References}

ACE, 1972. Systematic Drilling and Blasting for Surface Excavations. US Army Corps of Engineers. Engineering Manual EM 1110-2-3800, Washington, DC.

Alfonso, K., Elsalim, M., King, M., Strellis, D., Gozani, T., 2013. MCNP simulation benchmarks for a portable inspection system for narcotics, explosives, and Nuclear material detection. IEEE Trans. Nucl. Sci. 60, 520-527.

AO [Online], 2015. $905 \mathrm{NaI}$ (Tl) Scintillation Detectors. 〈http://www.ortec-online.com/ products/radiation-detectors/scintillation-detectors/scintillationdetector-types/905series $>$. AMETEK ORTEC. (Reviewed on August 2017).

ATI [Online], 2016. DD110M and DD109M. 〈http://www.adelphitech.com/products/ dd109m-dd110m.html $>$ Adelphi Technology, Inc. (Reviewed on August 2017).

Bedogni, R., Pietropaolo, A., Gomez-Ros, J., 2017. The thermal neutron facility HOTNES: theoretical design. Appl. Radiat. Isot. 127, 68-72.

Bergaoui, K., 2015. Le developpement des techniques analytiques nucleaires autour d'un generateur de neutrons deuterium-deuterium (D-D). Thèse de doctorat Université de Tunis El Manar, Tunis.

Bergaoui, K., Renguigui, N., Gary, C.K., Brown, C., Cremer, J.T., Vainionpaa, J.H., Piestrup, M.A., 2014. Monte Carlo simulation of explosive detection system based on a Deuterium-Deuterium (D-D) neutron generator. Appl. Radiat. Isot. 94, 118-124.

Bernaola Alonso, J., Castilla Gómez, J., Herrera Herbert, J., 2013. Perforación y voladura de rocas en minería. E.T.S. de Ingenieros de Minas de Madrid. Universidad Politécnica de Madrid, Madrid.

Canberra [Online], 2017. NAIS-3X3-NaI(TI) LED Temperature-Stabilized Scintillation Detector. 〈http://www.canberra.com/products/detectors/scintillation-detectors. asp> (Reviewed on August 2017).

Chichester, D.L., 2009. Production and Applications of Neutrons Using Particle Accelerators. Idaho National Laboratory, pp. 243-295 Report INL/EXT-09-17312.

Chichester, D.L., Blackburn, B.W., 2007. Radiation fields from neutron generators shielded with different materials. Nucl. Instrum. Methods Phys. Res. B 261, 845-849.
Cremer, J.T., Piestrup, M.A., Gary, C.K., Harris, J.L., Jones, G., Vainionpaa, J.H., Fuller, M.J., Williams, D., Rothbart, G.H., Kwan, J.W., Ludewigt, B.A., Gough, R., Reijonen, J., Leung, K-N., 2008. High Brightness Neutron Source for Radiography. Final report phase II DOE STTR. Award number DE-FG02-04ER86177, pp. 1-18.

Gozani, T., 1997. Inspection techniques based on neutron interrogation. SPIE Proc. 2936, 9-20.

Hakimabad, H.M., Panjeh, H., Vejdani-Nogheiyan, A., 2007. Evaluation the nonlinear response function of a $3 \times 3$ in NaI scintillation detector for PGNAA applications. Appl. Radiat. Isot. 65, 918-926.

Hernandez-Adame, L., Contreras-Sandoval, H., Vega-Carrillo, H.R., Perez-Landeros, L.H., 2010. Design of a treatment room for an 18-MV linac. Nucl. Technol. 175, 105-112.

ICRP, 1996. Conversion coefficients for use in radiological protection against external radiation. Ann. ICRP 26, 200 ICRP Report 74.

Jackson, S.I., 2017. The dependence of ammonium-nitrate fuel-oil (ANFO) detonation on confinement. Proc. Combust. Inst. 36, 2791-2798.

Kuznetsov, A.V., Evsenin, A.V., Gorshkov, I.Y., Osetrov, O.I., Vakhtin, D.N., 2004 Detection of buried explosives using portable neutron sources with nanosecond timing. Appl. Radiat. Isot. 61, 51-57.

Parra Terraza, S., Lara Murrieta, P., Villarreal Romero, M., Hernández Verdugo, S., 2012. Crecimiento de plantas y rendimiento de tomate en diversas relaciones nitrato/ amonio y concentraciones de bicarbonato. Rev. Fitotec. Mex. 35, 143-153.

Pelowitz, D.B., Fallgren, A.J., McMath, G.E. (Eds.), 2014. MCNP6 ${ }^{\text {TM }}$ - User's manual, Version 6.1.1beta. Los Alamos National Laboratory, New Mexico.

Podgorsak, E.B., 2016. Radiation Physics for Medical Physicists, 3rd edition. Springer International Publishing, Switzerland.

Runkle, R.C., White, T.A., Miller, E.A., Caggiano, J.A., Collins, B.A., 2009. Photon and neutron interrogation techniques for chemical explosives detection in air cargo: a critical review. Nucl. Instrum. Methods Phys. Res. A 603, 510-528.

Sakurai, Y., Sasaki, A., Kobayashi, T., 2004. Development of neutron shielding material using metathesis-polymer matrix. Nucl. Instrum. Methods Phys. Res. A 522, 455-461.

Salgado, C.M., Brandao, L.E., Schirru, R., Pereira, C.M., Conti, C.C., 2012. Validation of a NaI(Tl) detector's model developed with MCNP-X code. Prog. Nucl. Energy 59, 19-25.

Schwarz, A., Schwarz, R., Carter, L., 2008. MCNP/MCNPX Visual Editor Computer Code Manual, 22S, pp. 1-350.

Sears, V.F., 1992. Neutron scattering lengths and cross sections. Neutron News 3 (Iss. 3), $26-37$.

Takahashi, Y., Misawa, T., Masuda, K., Yoshikawa, K., Takamatsu, T., Yamauchi, K., Shiroya, S., 2010. Development of landmine detection system based on the measurement of radiation from landmines. Appl. Radiat. Isot. 68, 2327-2334.

Vega-Carrillo, H.R., Martinez-Ovalle, S.A., 2016. Few groups neutron spectra, and dosimetric features, of isotopic neutron sources. Appl. Radiat. Isot. 117, 42-50.

Vega-Carrillo, H.R., Guzmán-García, K.A., Gallego, E., Lorente, A., 2014. Passive neutron area monitor with pairs of TLDs as neutron detector. Radiat. Meas. 69, 30-34.

Yasin, T., Nasir, K.M., 2008. High density polyethylene/boron carbide composites for neutron shielding. e-Polymers $8,1-7$. 